\title{
UNTIL, Aspect, and Negation: A Novel Argument for Two Untils
}

\author{
Anastasia Giannakidou \\ University of Chicago and University of Groningen
}

\section{Outline of the argument}

The puzzle of English until is well-known. Karttunen 1974 argues that until is ambiguous between a durative and a punctual negative polarity (NPI) meaning. Mittwoch 1977 claims that there is no ambiguity and that the two meanings are due to scope differences: NPI-until is in fact until above negation. Mittwoch's account relies crucially on the assumption that negation is an aspectual operator that 'stativizes' verb meanings (a position recently argued for in de Swart 1996, and de Swart and Molendijk 1999; see also Klima 1964, Seuren 1974, Verkuyl 1993). Thus far, the correct analysis of until remains an open issue.

In this paper, I revisit until by exploring first the semantics of its Greek counterpart mexri. (I use the convention 'UNTIL' to refer to the connective crosslinguistically.). Looking at Greek can be helpful because this language exhibits overt aspectual marking (perfective-imperfective), thereby allowing us to compare the two opposing accounts by testing the validity of the hypothesis that serves as the basis for one of them: that negation is an aspectual operator. Novel data are presented showing that mexri cannot be used with negated nonstative perfective forms. In this case, a distinct scalar NPI is used-para monon. This fact challenges the one until account, and provides grounds for a novel argument for two untils since we have evidence for a lexical distinction; it also shows that negation cannot 'undo' what overt aspect did first. This result is further supported by the usual diagnostics of stativity which show that negated perfectives, the English simple past included, are not stative.

Contrary to what is believed (Mittwoch 1974, de Swart 1996), we will see that the two until and the scopal analysis are not equivalent under negation. The wide-scope UNTIL analysis, but not the NPI-analysis, posits a true stative reading which does not imply actualization of an event. While this reading is available with imperfective forms in Greek (negated and not), crucially, it is a reading that negated simple past sentences in English lack. This renders Mittwoch's account untenable for negative sentences with until. Karttunen's two-until thesis is, then, the only possible analysis for English.

The paper is organized as follows. In section 2, I present the basic facts about until and the details of the opposing analyses. In section 3 the aspectual system of Greek is presented, with emphasis on the perfective-imperfective contrast and the effects it has on verb meanings. In 3.2, we identify the Greek counterpart of durative until, mexri, and illustrate that it is incompatible with negated perfective verb forms, thus falsifying the stative analysis of negation. Further diagnostics will be applied in section 5 to support this conclusion. With negated perfectives a distinct NPI is used-para monon-which differs from mexri in that it entails actualization of an event, in accordance with Karttunen. In section 4, we look at the interaction between negation, statives and UNTIL: it is shown that the English simple past behaves like a perfective and licenses only the NPI-until. Finally, is section 6, mexri and prin 'before' are compared, in the light of Karttunen's thesis that until and before are equivalent under negation. We note substantial differences between the two; Karttunen's equivalence is a by-product of scalarity, a feature common to both until and before.

(C) 2002 by Anastasia Giannakidou

B. Jackson (ed), SALT XII 84-103, Ithaca, NY: Cornell University. 


\section{The until-debate}

Until modifies states or processes (Karttunen 1974, Mittwoch 1977, Hitzeman 1991, de Swart 1996 and references), i.e. durative eventualities. Achievements and accomplishments, on the other hand, are incompatible with until.

(1) The princess slept until midnight.

(2) The princess was writing a letter until midnight.

(3) $\quad *$ The princess arrived until midnight.

(4) *The princess ate a sandwich until noon.

I will use the labels 'eventives' for achievements and accomplishments, and 'statives' for states and activities. The generalization, then, is that until is compatible with stative but not with eventive verb forms.

Typically, the until phrase introduces an interval with a well-defined endpoint $\beta$ (Hitzeman 1991), supplied by the clock expression contained in the until-phrase. (I will not discuss clausal until, but assume that what I say for phrasal until carries over to the clausal one with only minor adjustments). The verb $\alpha$ contributes a state which is then mapped onto the until-interval:

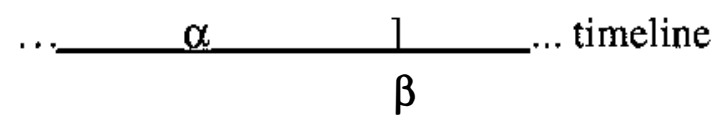

States are homogeneous(Bennett and Partee 1972), hence the state predicate is true at all subintervals of the until interval. This is reflected in the semantics in (6), from de Swart 1996 (building on earlier work from Hans Kamp):

$$
\begin{aligned}
& \text { Semantics for durative until } \\
& \text { For } \alpha: \lambda s[\mathbf{P}(s) \wedge \exists t \mathbf{A T}(s, t)] ; \quad \beta: \lambda t^{\prime} \mathbf{Q}\left(t^{\prime}\right) \\
& {\left[\left[\text { until }^{\prime}(\alpha, \beta)\right]\right]=\lambda s \exists t \exists t^{\prime} \exists t^{\prime \prime},\left[\mathbf{P}(\mathrm{s}) \wedge \mathbf{A T}\left(s, t^{\prime \prime}\right) \wedge \mathbf{Q}\left(t^{\prime}\right) \wedge t \subseteq t^{\prime \prime}{ }^{\prime} \wedge \forall t^{\prime \prime},\right.} \\
& \left.\left[\left[t \leq t^{\prime \prime}<t^{\prime}\right] \rightarrow \exists s^{\prime}\left[s^{\prime} \subseteq s \wedge \mathbf{P}\left(s^{\prime}\right) \wedge \mathbf{A T}\left(s^{\prime}, t^{\prime \prime}\right)\right]\right]\right]
\end{aligned}
$$

The until interval extends from some (not necessarily well defined) point $t$ to a point $t^{\prime}$ which is the time of the clock description $\mathrm{Q}$ provided by the until phrase. This semantics also captures the scalar nature of until. The connective introduces a range of values on the time scale. These are the times t" which precede the time $\mathrm{t}^{\prime}$. The verb contributes a state $\mathrm{P}$, and $\mathrm{P}$ is asserted to hold at all subintervals t' prior to t'. This semantics implies that there is a change of state at $\mathrm{t}^{\prime}$, the time indicated by the until phrase, and that $\mathrm{P}$ does not hold at $\mathrm{t}^{\prime}$. This, however, is at best a Q-implicature in the sense of Horn (1989), and as such it can be cancelled, as in (7):

$$
\text { Sure, the princess slept until midnight. In fact she only woke up at 2am. }
$$

Hence it seems appropriate to include t' in the P-holding interval; I indicate this by using a square bracket in (5). The scalar condition in the definition will be modified accordingly as $t \leq t^{\prime \prime} \leq t^{\prime}$ instead of the existing $t \leq t^{\prime \prime}<t^{\prime}$. The fact 
that there is no logical inference for a change of state with stative until will become important later in the discussion of the impact of negation.

The data in (1)-(4) follow directly: (1) and (2) are fine because they contain statives and satisfy the homogeneity condition; but the eventives in (3) and (4) are bad because events are either quantized (accomplishments) or have no duration at all (achievements), and do not validate the subinterval condition posited by until.

Curiously, the contrast between statives and eventives is neutralized with negation; eventive and stative verbs accept until if negated:

a The princess didn't arrive until midnight.
b The princess didn't sleep until midnight.

The stative ( $8 \mathrm{~b})$ can be argued to have the following structure:

$$
\begin{aligned}
& {[[(8 \mathrm{~b})]]=\exists s \exists t \exists t t^{\prime} \exists t^{\prime \prime},\left[\left(\neg \text { sleep) (princess, s) } \wedge \mathbf{A T}\left(s, t^{\prime \prime \prime}\right) \wedge t^{\prime \prime}<n\right.\right.} \\
& \wedge \text { midnight }\left(t^{\prime}\right) \wedge t \subseteq t^{\prime \prime \prime} \wedge \forall t^{\prime \prime}\left[[ t \leq t ^ { \prime \prime } \leq t ^ { \prime } ] \rightarrow \exists s ^ { \prime } \left[s^{\prime} \subseteq s \wedge(\neg\right.\right. \\
& \text { sleep) (princess, } \left.\left.\left.\left.s^{\prime}\right) \wedge \mathbf{A T}\left(s^{\prime}, t^{\prime \prime}\right)\right]\right]\right]
\end{aligned}
$$

Here the princess was in a state of not sleeping that stretches at the interval that ends at midnight. The bracketing ( $\neg$ sleep) (from de Swart 1996) indicates that negation operates on the verb meaning alone. Since we have a stative meaning, there is no change of state (recall the positive verb (7)), i.e. it should not be an implication of (8b) that there was a falling asleep event. (Whether this is indeed the correct semantics for the English sentence will be further discussed in 4.3). But what about (8a)? Is it plausible to assume that its meaning is parallel?

$$
\begin{aligned}
& {[[(8 \mathrm{a})]]=\exists s \exists t \exists t^{\prime} \exists t^{\prime \prime},[(\neg \text { arrive }) \text { (princess, } s) \wedge \mathbf{A T}\left(s, t^{\prime \prime \prime}\right) \wedge t^{\prime \prime}{ }^{\prime}<n} \\
& \wedge \text { midnight }\left(t^{\prime}\right) \wedge t \subseteq t^{\prime \prime} \wedge \forall t^{\prime \prime}\left[[ t \leq t ^ { \prime \prime } \leq t ^ { \prime } ] \rightarrow \exists s ^ { \prime } \left[s^{\prime} \subseteq s \wedge(\neg\right.\right. \\
& \text { arrive) (princess, } \left.\left.\left.\left.s^{\prime}\right) \wedge \mathbf{A T}\left(s^{\prime}, t^{\prime \prime}\right)\right]\right]\right]
\end{aligned}
$$

This meaning implies a temporal scheme like (11): there was an interval ending at midnight, and a state of not-arriving occupied that interval. For this to work, negation would have to operate on the verb meaning alone (see the bracketing), and alter the eventuality type: an eventive verb would become stative. Again, the existence of an arriving event should be at most an implicature.

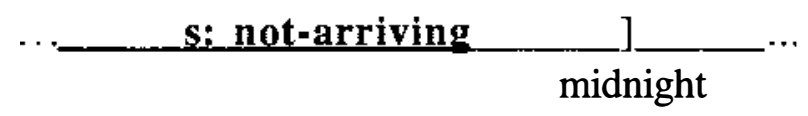

Mittwoch 1977 proposed that this is exactly the reading of (8a)-- but we will see that this cannot be right. Karttunen 1974 argued that until with negation does not have the semantics in (9) and (10). Rather, with negation we have an eventive until, which is homophonous to the stative one, and implies that there was an event of arrival or an event of falling asleep respectively (see also Hitzeman 1991, Declerk 1995, Tovena 1995, Clark in prep. for variants of this idea). The two-until analysis does not assign any special status to negation, other than signaling the beginning of an interval starting at the until-time.

Let us compare now the two analyses in more detail. 


\subsection{The one until approach}

The main ingredients of the one until approach can be summarized as follows:

(a) Negation is an aspectual modifier: a stativizer. It takes verbal forms of any eventuality type as its input, and gives back a state.

(b) There is scope interaction between until and negation, and the differences in the interpretation can be derived from this interaction alone.

(c) There are two scoping possibilities: we can scope until either above negation, or below negation. The first option gives the meaning of until that corresponds to Karttunen's NPI reading. The second, results in a wide scope negation which takes the until phrase in its scope.

Consider again our sentences in (8).

(8) a The princess didn't arrive until midnight.

b The princess didn't sleep until midnight.

Scoping until above negation yields the bracketing in (12). This is interpreted as in the indicated paraphrase which corresponds to the semantics we just discussed, repeated here as (13):

Mittwoch reading: wide scope until

until-midnight $[\neg$ arrived (the princess) $]=$

Until midnight, the princess was in a state of not-arriving.

$[[(8 \mathrm{a})]]=\exists s \exists t \exists t t^{\prime} \exists t t^{\prime \prime},\left[\left(\neg\right.\right.$ arrive) (princess, s) $\wedge \mathbf{A T}\left(s, t^{\prime \prime \prime}\right) \wedge t t^{\prime \prime}<<n$ $\wedge$ midnight $\left(t^{\prime}\right) \wedge t \subseteq t^{\prime \prime \prime} \wedge \forall t^{\prime \prime}\left[\left[t \leq t^{\prime \prime} \leq t^{\prime}\right] \rightarrow \exists s^{\prime}\left[s^{\prime} \subseteq s \wedge(\neg\right.\right.$ arrive) (princess, $\left.\left.\left.\left.s^{\prime}\right) \wedge \mathrm{AT}\left(s^{\prime}, t^{\prime \prime}\right)\right]\right]\right]$

We can call this 'the Mittwoch reading'-it is supposed to be available with both eventives and statives, as we saw.

until-midnight $[\neg$ slept (the princess)]=

Until midnight, the princess was in a state of not-sleeping.

In the Mittwoch reading, the verbs contribute stative predicates in both cases. As with positive statives, this reading of negative 'statives' should not entail a change of state at the until time. In other words, an inference like the one in (15), where there was indeed an event of the princess's arriving that took place at the until-time (and not before that), should be impossible:

(15) The princess arrived at midnight and not before that.

$\exists e \exists t$ [ midnight $(t) \wedge t<n \wedge$ arrive (princess, $e, t)] \wedge \neg \exists e^{\prime} \exists t^{\prime} \quad\left[t^{\prime} \in \mathrm{C} \wedge\right.$

$t^{\prime}<t \wedge$ arrive (princess, $\left.\left.e^{\prime}, t^{\prime}\right)\right]$

In the Mittwoch reading the actualization inference is at most an implicature, which can be cancelled-- just like with with positive statives, as we saw in (7). De Swart tries to stipulate actualization as an entailment in this reading, but such an attempt will be contradicted by the Greek and French data that we discuss in sections 3 and 4, which show that negated imperfectives are 
indeed identical to positive verbs in the sense of (7).

In the second reading until scopes under negation, and negation is the regular external negation. This is not an option with eventives: in this position negation would not be able to affect the VP and alter its eventuality type:

$\neg$ [until midnight [ arrived (the princess)]]=

* The princess arrived, but not until midnight.

(Unavailable)

$\neg$ [until midnight [ slept (the princess)]] $=$

The princess slept, but not until midnight. She woke up (a little) earlier than that, e.g. at 11 .

Negation here can also be read metalinguistically, yielding an upper-bound reading (Horn 1989): the princess may have woken up later than midnight; but this is arguably a less salient reading which will be harmless to ignore. The semantics looks like (18): the state of the princess's sleeping did not hold at all times t' prior to the midnight time t'.

$$
\begin{aligned}
& \exists s \exists t \exists t t^{\prime} \exists t^{\prime \prime},\left[\text { sleep (princess, s) } \wedge \mathbf{A T}\left(s, t^{\prime \prime \prime}\right) \wedge t^{\prime \prime}{ }^{\prime}<n \wedge\right. \text { midnight } \\
& \left(t^{\prime}\right) \wedge t \subseteq t^{\prime \prime \prime} \wedge \neg \forall t^{\prime \prime}\left[\left[t \leq t^{\prime \prime}<t^{\prime}\right] \rightarrow \exists s^{\prime}\left[s^{\prime} \subseteq s \wedge \text { sleep (princess, } s^{\prime}\right)\right.
\end{aligned}
$$

$\left.\left.\left.\wedge \mathbf{A T}\left(s^{\prime}, t^{\prime \prime}\right)\right]\right]\right]$

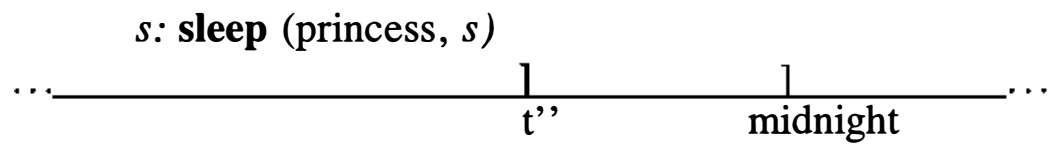

The one until hypothesis, then, makes the following predictions:

1. If a language has a connective UNTIL which conforms to the pattern in (1)-(4), it will also be used in cases like (8a) with negated eventives.

2. Lexical or other aspect should not matter: sentences with negative eventive forms, as well as those with negative statives, should have the Mittwoch reading and lack the actualization in (15).

We will see that both predictions fail. Prediction 1 fails on crosslinguistic grounds. Prediction 2 is shown to be wrong even for English: English negative sentences with until lack the Mittwoch reading and entail actualization.

\subsection{The two until analysis}

Karttunen argues that until with negation is different from the durative modifier until we see in the original paradigm (1)-(4). Until with negation is not durative but punctual: it entails actualization, as in (15), even with stative verbs. Because it is punctual, NPI-until yields an inchoative meaning in this case ${ }^{1}$ :

(20) The princess did not sleep until midnight. = The princess fell asleep at midnight.

In this reading there is indeed an event of princess's falling asleep at midnight. (Or at little later than that, as Karttunen notes; we can overlook this detail as it is not crucial for the present purposes. Additionally, Kartunnen assumes that the event inference is a presupposition, but we can safely gloss over this too). This 
is in clear contrast with the Mittwoch reading, and indeed the reading that negated statives have. More evidence will be provided below when we consider the Greek data, but the fact should already be obvious for English.

Punctual until, then, is an negative polarity item (NPI) triggered by negation and interpreted inside the scope of negation with both eventives and statives. Karttunen argues also that NPI-until is equivalent to before under negation, but we see in section 6 that this point needs to be revised.

Actualization is responsible for the oddity of (21a), Karttunen's (23):

a \# Nancy didn't get married until she died.

b $\exists t \exists e \exists e^{\prime}$ [die (Nancy, $\left.e, \mathrm{t}\right) \wedge t<n \wedge$ get-married (Nancy, $\left.e^{\prime}, t\right) \wedge \neg \exists e^{\prime \prime} \exists t^{\prime}\left[t^{\prime}<t \wedge\right.$ get-married (Nancy, $\left.\left.\left.e^{\prime \prime}, t^{\prime}\right)\right]\right]$

Here, Nancy both dies and gets married at the same time $t$, hence the oddity. This contrasts clearly with the sentence below with a true stative.

Nancy remained a spinster until she died.

(Karttunen 1977: (21))

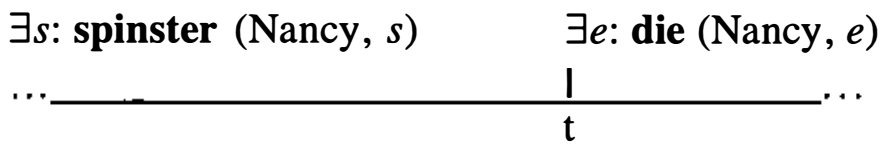

If not get married were equivalent to the stative remain a spinster, as argued by Mittwoch, we should not get a contrast. But, in agreement with what we noted for statives, the sentence with remain a spinster lacks the event inference that yields a getting married event. So, Nancy doesn't get married at the moment of dying and the sentence is perfectly reasonable.

Negation has thus no special effect on the eventuality type of the verb in the two until thesis. It is furthermore predicted that there may be languages employing a distinct lexical item for the NPI-meaning, and, even stronger, that such languages might exclude the non-NPI item with negated eventives. We see immediately that Greek confirms both predictions.

\section{Greek UNTIL}

In this section we look at the Greek facts concerning UNTIL, providing first the necessary background on tense and aspect in Greek.

\subsection{Background on tense and aspect in Greek}

The Greek verb is obligatorily inflected for tense and aspect. The four possibilities are given in (23) (cf. Mackridge 1985, Holton et al. 1997):

(23) a. graf- $\quad$-o (INP)

write.imperf -1sg.nonpast

'I am writing (right now).'

'I write (generally).' b. grap- s- -o (PNP)

write- perf $.1 \mathrm{sg}$.nonpast

[no English equivalent] 
(24) a. e- graf- -a (IP)

past- write.imperf $-1 \mathrm{sg}$.past

'I used to write.'

'I was writing.' b. e- grap- s- a (PP)

past- write- perf.1sg.past

'I wrote.'

The basic temporal opposition is between a morphological past, which is marked by the prefix $e$ - attaching to the verbal stem, and a nonpast which is signaled by the absence of the prefix $e$-(hence the label nonpast). Aspectual choice in Greek is unavoidable in all tenses (including the future).

As I proposed in earlier work, perfective aspect takes a bare verb meaning-- bare in the sense that it contains just the lexical entry and its argument slots, as in (25c)-- and gives back a predicate of events, as indicated in (25b): ${ }^{2}$

$$
\begin{array}{ll}
\text { a. } & \text { PFT }[P]=\lambda \mathrm{x} \lambda \mathrm{y} \lambda \mathrm{e} \exists \mathrm{t}[\mathrm{P}(\mathrm{y}, \mathrm{x}, \mathrm{e}) \wedge \mathrm{e} \subseteq \mathrm{t}] \\
& \text { (Giannakidou 2002) } \\
\text { b. } & {[[\mathrm{PFT}]]=\lambda \mathrm{P} \lambda \mathrm{e} \exists \mathrm{t}[\mathrm{P}(\mathrm{e}) \wedge \mathrm{e} \subseteq \mathrm{t}]} \\
\text { c. } & {[[\mathrm{P}(\mathrm{x}, \mathrm{y})]]=\lambda \mathrm{x} \lambda \mathrm{y} P(\mathrm{y}, \mathrm{x})}
\end{array}
$$

Events can take time to culminate (accomplishments), in which case $t$ is an interval; or they start and culminate at the same time (achievements), in which case $t$ is an instant. The condition ' $\mathrm{e} \subseteq \mathrm{t}$ ' expresses the relation that e takes place at $t$ (cf. the AT relation we've been using so far, from Krifka 1989); the same thing can be expressed by including $t$ as an argument of the verb (which is another variant I will be using here). At a higher level, tense contributes the information that the event is located in the past $(\mathrm{t}<\mathrm{n})$, or in the future $(\mathrm{n}<\mathrm{t})$; or at some interval that includes $n(o w)$, the utterrance time. The perfective nonpast does not occur as a free standing form-roughly, because PNP cannot locate an event in time: it cannot locate it in the past, since it is non-past, but it can't locate an event in the present or the future either. This is so because PNP lacks tense specification, and the present is not available since now is an interval and blocks a perfective form (see Giannakidou and Zwarts for more details). ${ }^{3}$

So, a typical sentence with past perfective is interpreted episodically; this is straightforward if the verb itself is eventive, as shown in (26):

$$
\begin{aligned}
& \text { a Ariadni filise ton Pavlo. } \\
& \text { the Ariadne kissed.perf.3sg the Paul } \\
& \text { 'Ariadne kissed Paul.' } \\
& \text { b } \exists \mathrm{e} \exists \mathrm{t}[\text { kiss (Ariadne, Paul, e) } \wedge \mathrm{t}<\mathrm{n} \wedge \mathrm{e} \subseteq \mathrm{t}]
\end{aligned}
$$

Statives can also be modified by the perfective-- but in this case the semantics of the perfective triggers an eventive reading, e.g.an achievement:

$$
\begin{aligned}
& \text { a. I Ariadni agapise ton Pavlo. } \\
& \text { Ariadne loved.perf.3sg the Paul. }= \\
& \text { 'Ariadne fell in love with Paul' } \\
& \text { b. } \exists \mathrm{e} \exists \mathrm{t} \text { [love (Ariadne, Paul, e) } \wedge \mathrm{t}<\mathrm{n} \wedge \mathrm{e} \subseteq \mathrm{t}]
\end{aligned}
$$


This is the inchoative reading: there is a falling in love event which is seen as an instantaneous event like e.g. notice. Activities, e.g. kimame 'sleep', also shift to achievement meanings: this happens in the sentence below, which contains a definite locating adverbial:
a. I Ariadni kimithike
stis enia.
Ariadne slept.perf.3sg at nine =
'Ariadne fell asleep at 9.'
b. $\exists \mathrm{e} \exists \mathrm{t}$ [sleep (Ariadne, e) $\wedge \mathrm{t}<\mathrm{n} \wedge \mathrm{e} \subseteq \mathrm{t} \wedge \mathrm{t}=9$ o'clock)]

Activities can also receive accomplisment-like readings with perfective aspect, as I noted in Giannakidou 2002, in which case the activity lasts for some time and then culminates at some point $t$.

$$
\begin{aligned}
& \text { a. I Ariadni kimithike ja mia ora. } \\
& \text { Ariadne slept.perf.3sg for an hour = } \\
& \text { 'Ariadne slept for an hour.' } \\
& \text { b. } \exists \mathrm{e} \exists \mathrm{t} \text { [sleep (Ariadne, } \mathrm{e}) \wedge \mathrm{e} \subseteq \mathrm{t} \wedge \text { one-hour }(\mathrm{i}) \wedge \mathrm{i}<\mathrm{n}]
\end{aligned}
$$

This reading is accomplishment-like but not exactly an accomplishment, since part of it (the activity) is homogeneous. We come back to this in section 4.2. The impact perfective aspect has on stative verbs will be important when we consider Karttunen's inchoative readings with UNTIL. The aspectual shifts we observe in Greek are not at all peculiar; comparable shifts are in fact quite common (see Zucchi 1998 for recent discussion and references). Since they are systematic, it makes sense to treat these shifts as the result of modification by aspect, rather than lexical ambiguities. At the lexical level, the V-meaning is bare, i.e. it does not contain any grammaticalized event information; it is aspect that contributes this information. ${ }^{4}$

The imperfective in Greek is typically ambiguous between the habitual and the progressive. The imperfective provides an interval, and the habitual generalizes over eventualities (events or states) in that interval. I omit consideration here, as it is not important at present (but see Giannakidou 2002).

The progressive creates true stative forms: it maps a state onto the interval provided by the imperfective aspect. I will assume that the (quite simplified) semantics in (30) will suffice for our purposes (the complications of the progressive are well-known and discussed in, at least, Bennett and Partee 1972, Bonomi 1997, Landman 1992, Zucchi 1999):

The progressive

$$
\text { PROG }[P]=\lambda s \exists \mathrm{i} \forall t[(\mathrm{t} \in \mathrm{C} \wedge t \subseteq i) \rightarrow \mathbf{P}(s, t)]
$$

\footnotetext{
a. I Ariadni filuse (imperf.) ton Pavlo ja pende lepta. 'Ariadne was kissing Paul for five minutes.'

b. $\exists$ s $\exists$ i [ five-minutes (i) $\wedge \mathrm{i}<\mathrm{n} \wedge \forall t \quad[(\mathrm{t} \in \mathrm{C} \wedge t \subseteq i) \rightarrow$ kiss (Ariadne, Paul, $s, t)]$ ]
} 
To summarize, Greek verb forms, unlike English, are unambiguouly stative or eventive, depending on whether they are perfective or imperfective. This property of Greek is useful when we check the effects of negation. If negation is a stativizer, e.g. like the progressive, it must be able to stativize a perfective and make it equivalent to a perfective. We see next that this is not the case.

\subsection{Mexri and para monon}

Greek possesses the lexical item mexri which, as we see in the examples below, modifies only durative eventualities, just like until:

I prigipisa egrafe ena grama mexri ta mesanixta. the princess wrote.imperf.3sg a letter until the midnight

'The princess was writing a letter until midnight.'

I prigipisa kimotane mexri ta mesanixta.

the princess slept.imperf.3sg until the midnight

'The princess was sleeping until midnight.'
* I prigipisa eftase
mexri ta mesanixta.
the princess arrived.perf. $3 \mathrm{sg}$
until the midnight
'*The princess arrived until midnight.'

The contrast here is the one we witnessed with until. Unlike until, however, mexri cannot be used with a negated achievement, which appears in the perfective, as we see in (35):
* I prigipisa dhen eftase
mexri ta mesanixta.
the princess not arrived.perf.3sg
until the midnight

'The princess did not arrive until midnight.'

Negation seems unable to 'stativize' an unambiguously eventive verb form. With such forms, a scalar NPI is used instead of mexri: para monon, lit. 'but only'. With a perfective stative, para monon triggers the expected achievement reading, which can also be marked with apo-prefixation as in (37):
I prigipisa $\quad *$ (dhen) eftase the princess not arrived.perf.3sg
para monon ta mesanixta.

'The princess did not arrive until midnight.'

$=$ It was only at midnight that the princess arrived.
I prigipisa dhen (apo)kimithike
para monon ta mesanixta. the princess not fell.asleep.perf.3sg but only the midnight

'The princess didn't fall asleep until midnight.

With para monon, we have the actualization entailment (15); negating the arrival leads to a contradiction, as we see in (38):

(38) \# I prigipisa dhen eftase para monon ta mesanixta.

the princess not arrived.perf.3sg but only the midnight

Dhen eftase kan ekino to vradi.

not arrived even that night 
‘\# The princess did not arrive until midnight. In fact she didn't even arrive that night.'

We can then conclude that para monon is the lexical realization of the eventive NPI-until that Karttunen has argued for. The semantics below captures this:

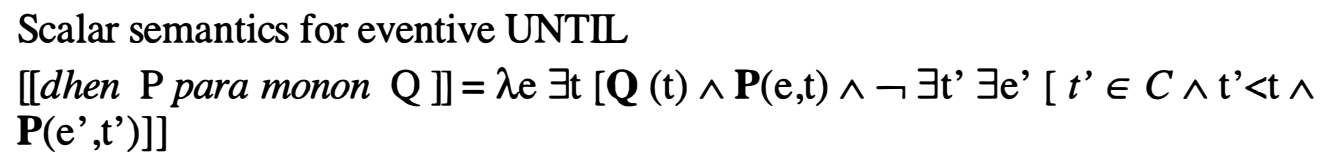

Eventive UNTIL contributes a scale of (contextually relevant) times t' leading to an endtime $t$, at which an event occurs. This is a purely scalar reading-- it is no accident that it involves an expression-- para monon-- that is scalar but not exclusively temporal (cf. French ne ... que which has a similar use). So Greek confirms the two until hypothesis by providing evidence for a lexical distinction between an eventive NPI-UNTIL (para monon) and a stative one (mexri).

Para monon is a negative PI in the sense of Giannakidou 1998, 1999: it is licensed only by antiveridical triggers, e.g. negation and 'without':

(40) Kitouse to tavani xoris na milisi para monon otan efije o jatros.

He staired at the wall without talking until the doctor left.

Other nonveridical elements, e.g.(41), do not allow para monon, but they do allow until (for more data, see de Swart 1996). Only the former, then, is an NPI proper. A negative implicature can't license para monon either; note the contrast with until in a rhetorical question:
Amfivalo an ixe erthi $\{*$ para monon/mexri\} ta mesanixta.
* I doubt whether he had arrived until midnight.
*Jati na pantreftis \{para monon/mexri\} otan prepi anagastika na to kanis?
Why marry until you absolutely have to?

These contrasts should be embedded in the general differences between English and Greek NPIs and other PIs (see my earlier works for more discussion). ${ }^{5}$

Let me close this section with some crosslinguistic observations. Greek is not the only language that employs a lexically distinct NPI-UNTIL; Icelandic is another such language (and so is Czech; Hana Filip, p.c.). The data below, from Gunnar Hansson, illustrate a contrast exactly parallel to the one we observe in Greek:
Prinsessan svaf $\{($ flanga $)$ til $\}$ klukkan fimm
princess-the slept mexri five o'clock
'The princess slept until five o'clock.'
Prinsessan var a skrifa bréf \{(flanga) til \} klukkan fimm.
princess-the was to writ letters mexri five o'clock
'The princess was writing letters until five o'clock.'
*Prinsessan kom \{(flanga) til $\}$ klukkan fimm
princess-the arrived until five o'clock
'The princess arrived until five o'clock.'
Prinsessan kom *(ekki)fyrr en
princess-the arrived not paramonon five o'clock
'The princess didn't arrive until five o'clock.' 
The expressions (flanga) til (flanga can be used to introduce clauses too) are just like mexri: they combine only with stative meanings. Achievements (and accomplishments), however, rule out flanga/til, and fyrr en lit. 'earlier than' is used instead (there is also a morphologically distinct word for BEFORE). The entailments are the same as in Greek; there is actualization of the event with fyrr en but not with flanga/til. Interestingly, Icelandic does not have overt verbal aspect, unlike Greek. This means that the aspect parameter is not decisive for whether or not a language will lexicalize the distinction between durative and eventive UNTIL - a not unexpected fact, given our assumption that the aspectual distinctions must be present at some level, even if not overtly so.

Other languages, e.g. German and Dutch, exclude durative UNTIL from negation altogether and employ a positive polarity item instead (Declerk 1995 for German). I illustrate this here with Dutch.
a
* Marie kwam tot 9 uur (niet) aan. Marie came until 9 hour (not) on Marie didn't arrive until 9.
b Marie kwam pas om 9 uur aan. Mary only arrived at 9 .

Dutch and German lexicalize the complex [not NPI-UNTIL] in a distinct expression: pas, erst, which can be treated as positive polarity item.

\section{Negation, overt aspect and statives: English versus Greek}

In this section we examine the interaction of UNTIL with negative statives. Statives can appear in either perfective or imperfective (progressive) and allow mexri:
I prigipisa dhen kimotane
mexri ta mesanixta. the princess not slept.imperf.3sg until the midnight

'The princess was in a state of not-sleeping until midnight.'

'It is not true that the princess slept until midnight.' (She woke up earlier than that.)
I prigipisa dhen kimithike
the princess not slept.perf. $3 \mathrm{sg}$
mexri ta mesanixta. until the midnight
'It is not true that the princess slept until midnight.' (She woke up earlier than that.)

The major finding will be that the stative Mittwoch reading, which implies no event actualization, is indeed possible with the negation of a stative verb, but only if the verb is imperfective (4.1). A negative perfective, on the other hand, even that of a stative, triggers the NPI-UNTIL with actualization (4.2). These onservations carry over to English: we see in 4.3 that wide scope until is not an option with negative statives, and hence not an option at all with the simple past. Crucially, the facts here show that the NPI-analysis and the wide-scope-UNTIL analysis are not equivalent under negation (pace Mittwoch 1977 and de Swart 1996), and that Karttunen's thesis is the only viable analysis for English. 


\subsection{Negation with imperfective: wide scope until}

The imperfective sentence (48) exhibits the two scopes postulated by Mittwoch. The first option is the Mittwoch reading with mexri taking wide scope:

$$
\begin{aligned}
& {[[(8 \mathrm{~b})]]=\exists s \exists t \exists t t^{\prime} \exists t^{\prime \prime},\left[\neg \text { sleep (princess, s) } \left[\mathbf{A T}\left(s, t^{\prime \prime}{ }^{\prime}\right) \wedge t^{\prime \prime}{ }^{\prime}<n \wedge\right.\right.} \\
& \text { midnight }\left(t^{\prime}\right) \wedge t \subseteq t^{\prime \prime \prime} \wedge \forall t^{\prime \prime}\left[[ t \leq t ^ { \prime \prime } \leq t ^ { \prime } ] \rightarrow \exists s ^ { \prime } \left[s^{\prime} \subseteq s \wedge(\neg \text { sleep }\right.\right. \\
& \text { (princess, } \left.\left.\left.\left.\left.s^{\prime}\right)\right) \wedge \mathbf{A T}\left(s^{\prime}, t^{\prime \prime}\right)\right]\right]\right]
\end{aligned}
$$

This is the truly stative reading, therefore we do not have an entailment that there was a falling asleep event at the until time. This becomes obvious in continuations like the one in (51b) below, where it is asserted that, at that time, the princess actually did something other than falling asleep:

$$
\begin{aligned}
& \text { I prigipisa dhen kimotane mexri ta mesanixta. } \\
& \text { the princess not slept.imperf.3sg until the midnight } \\
& \text { 'The princess was in a state of not-sleeping until midnight.' }
\end{aligned}
$$

b Ke tote, apofasise na sikothi, na ndithi ke na vgi ekso.

And then she decided to get out of bed, get dressed, and go out for a walk.

The same is reported for French jusqu’a (Vogeleer 1999: ex. (34)). In French, the stative occurs not in the imperfective but in the perfect, another stative form.

(52) Jean n' a pas dormi jusqu' à 9 heures. A 9 heurs, il s'est habillé et il est allé se promener.

Since this is the wide scope UNTIL reading, the mexri adverbial can be preposed overtly without altering the status of continuations like (51b) above.

$$
\begin{aligned}
& \text { (Mexri ta mesanixta) i prigipisa dhen kimotane. } \\
& \text { Until the midnight the princess not slept.imperf. } 3 \mathrm{sg} \\
& \text { 'Until midnight, the princess was in a state of not-sleeping.' } \\
& \text { NOTE: *Until midnight, the princess didn't sleep. }
\end{aligned}
$$

Cont: Ke tote, apofasise na sikothi, na ndithi ke na vgi ekso.

Then she decided to get out of bed, get dressed and go out for a walk.

This reading is different from the one with para monon, which entails actualization. Note that the English version of preposed until in (53) is not good, indicating that did not sleep is not intepreted as an imperfective form. We will come back to this shortly.

In the second reading, negation scopes over mexri:

(54) $[[(48)]]=[\neg$ until midnight [sleep (the princess) $]$

It is not true that the princess slept until midnight. She woke up earlier than that.

(55) $\exists s \exists t \exists t t^{\prime} \exists t \prime$, [sleep (princess, s) $\wedge \mathbf{A T}\left(s, t^{\prime \prime \prime}\right) \wedge t^{\prime \prime \prime}<n \wedge$ midnight $\left(t^{\prime}\right) \wedge t \subseteq t^{\prime \prime}{ }^{\prime} \wedge \neg \forall t^{\prime \prime}\left[\left[t \leq t^{\prime \prime} \leq t^{\prime}\right] \rightarrow \exists s^{\prime}\left[s^{\prime} \subseteq s \wedge\right.\right.$ sleep (princess, $\left.s^{\prime}\right)$ $\left.\left.\left.\wedge \mathbf{A T}\left(s^{\prime}, t^{\prime \prime}\right)\right]\right]\right]$ 
Here, the princess was in a state of sleeping, which, however did not last through the whole mexri interval. Ignoring metalinguistic negation, the regular implication is that the princess woke up earlier.

To conclude this section, (a) the scope analysis is indeed appropriate for Greek negated imperfectives; (b) English simple past lacks the stative reading.

\subsection{Negation with the perfective: mexri versus para monon}

The Mittwoch reading is disallowed with a perfective stative; instead we get only the external negation reading that we just described:
I prigipisa
dhen kimithike
mexri ta mesanixta. the princess not slept.perf.3sg until the midnight

'It is not true that the princess slept until midnight. She woke up earlier than that.

In this reading, (56) is synonymous to the imperfective (48): the only difference is that in the perfective version we have the feeling that what is negated is that the culmination of the sleeping happened at midnight. But this contributes no truth-conditional effect. The reading of sleeping as a culminated event is triggered by the perfective, in accordance with what we described in section 3 .

It may be reasonable to ask why this reading allows mexri at all, in contrast with accomplishements like ??I prigipisa ipie enan kafe mexri ta mesanixta 'The princess drank a cup of coffee until midnight', which don't. As we noted in section 2, accomplishments are bad with durative UNTIL because they are quantized. Perfective activities, however, are more like complex events comprising a homogeneous part (the activity) and its culmination; this allows partial mapping on the UNTIL interval. To the extend that such complex readings are possible with accomplishements in general, we expect them indeed to allow occassionally for durative UNTIL, and it is true that accomplishments often give mixed results; e.g. note that the sentence I just gave is not as bad as the negation of an achievement (which is *, cf. (35)). Space prevents me from further elaborating on this issue here.

Compare now (56) to the version with para monon, where there is obligatory shift to an achievement meaning, in agreement with the semantics we postulated in (39). We have actualization of a falling-asleep event, and continuations canceling this are contradictory.

I prigipisa dhen kimithike para monon ta mesanixta. the princess not slept.perf.3sg but only the midnight

'The princess didn't sleep until midnight.

$=$ It was only at midnight that the princess fell asleep.

Cont: \# Ke tote, apofasise na sikothi, na ndithi ke na vgi ekso.

And then she decided to get out of bed, get dressed and go out for a walk.

$$
\begin{aligned}
& \exists e \exists t[\text { midnight }(t) \wedge t<n \wedge \text { fall-asleep (princess, } e, t)] \wedge \neg \exists e^{\prime} \exists t^{\prime} \\
& \left.\left[t^{\prime} \in \mathrm{C} \wedge t^{\prime}<t \wedge \text { fall-asleep (princess, } e^{\prime}, t^{\prime}\right)\right]
\end{aligned}
$$

We can then safely conclude the following:

1. Wide-scope and NPI-UNTIL are not equivalent under negation. The NPI para monon entails actualization, but wide-scope UNTIL does not, 
because it has a true stative reading. This is evidenced by the fact that wide scope UNTIL is compatible with continuations asserting the absence of an event. In this reading, UNTIL can also precede negation overtly.

2. Only imperfective forms allow the wide-scope UNTIL reading. Perfective forms allow only the NPI-reading and the narrow scope UNTIL.

\subsection{What about English?}

The analysis of English should now be obvious. With statives we have the readings we get in Greek with the perfective form. The first option is the wide scope negation, where the princess does not sleep at all subintervals t', and wakes up before midnight:

The princess didn't sleep until midnight.

$$
\begin{aligned}
& \exists s \exists t \exists t^{\prime} \exists t^{\prime \prime}, \quad\left[\text { sleep (princess, }, t^{\prime \prime \prime}\right) \wedge t^{\prime \prime},<n \wedge \text { midnight }\left(t^{\prime}\right) \wedge t \subseteq \\
& \left.\left.t^{\prime \prime}, \wedge \neg \forall t^{\prime \prime}\left[\left[t \leq t^{\prime \prime} \leq t^{\prime}\right] \rightarrow \exists s^{\prime}\left[s^{\prime} \subseteq s \wedge \text { sleep (princess, } s^{\prime}, t^{\prime \prime}\right)\right]\right]\right]
\end{aligned}
$$

The second reading is the NPI-reading, as is witnessed by the fact that we have a contradictory continuation, and preposing of until is not allowed:

(61) a. The princess didn't sleep until midnight. \# At midnight she got up, got dressed and went out for a walk.

b. *Until midnight, the princess didn't sleep.

Recall from 4.1. that the wide scope UNTIL reading was available with imperfective statives in Greek leading to non-contradictory continuations, and allowing preposing. The English simple past obviously lacks this reading. This suggests that the English simple past behaves like an perfective. Because there is no aspectual marking in the English past tense, and in the absence of additional contextual information, we must assume, then, that the default value is perfective (see Katz 2000 for postulating a perfective in syntax). Although this is fairly obvious with events, it is not so obvious when we consider states. But note that states are often shifted to the get-state reading in the simple past:

$$
\begin{array}{ll}
\text { a John hit Bill. } & \text { (vs. John used to hit Bill). } \\
\text { b John was often sick.= } \\
\text { John got often sick. }
\end{array}
$$

Space prevents more discussion-- but recall that Dutch and German, which are very similar to English vis-à-vis aspectual marking, do have perfective default values in the past and render the UNTIL- word ungrammatical.

With non-statives, again we have only the NPI reading, as expected:

(63) The princess didn't arrive until midnight.

(64) $\exists e \exists t$ [ midnight $(t) \wedge t<n \wedge$ arrive (princess, $e, t)] \wedge \neg \exists e^{\prime} \exists t^{\prime}$

$$
\left.\left[t^{\prime} \in \mathrm{C} \wedge t^{\prime}<t \wedge \text { arrive (princess, } e^{\prime}, t^{\prime}\right)\right]
$$

The conclusion is unavoidable: Mittwoch's wide scope until is not available in English. Karttunen's analysis is, then, the only possible analysis for until and negation. This conclusion threatens directly the account of negation as a stativizer. 


\section{Consequences for the analysis of negation}

The idea that negation is a verb modifier which stativizes the verb meaning is recently revived in de Swart 1996 and de Swart and Molendijk 1999, where negation is treated as a VP-modifier yielding maximal states of the form below:

$$
\begin{aligned}
& \lambda P \lambda s[\operatorname{MAX}(s) \wedge \neg \exists e[\mathrm{P}(e) \wedge e \subseteq s]] \quad \text { (de Swart 1996, (32)) } \\
& \forall e\left[\operatorname{MAX}(e) \leftrightarrow \exists t\left[e=\sup _{\mathrm{e}}\left(\lambda e^{\prime} \exists t^{\prime}\left(\mathrm{AT}\left(e^{\prime}, t^{\prime}\right) \wedge t^{\prime} \subseteq t\right)\right)\right]\right] \\
& \text { (based on Krifka 1989) }
\end{aligned}
$$

According to (65), negation takes an eventuality description $\mathrm{P}$ as its input and yields a maximal state $s$ such that no eventuality e of type $P$ is contained in $s$. We just saw that negation fails to create such maximal states with the English simple past and Greek perfective forms. I consider here additional tests that strengthen this conclusion.

Consider first the how long test, already presented in Karttunen 1974:
a
(Ja) Posi ora kimotane
i Ariadne?
For how time slept.imperf.3sg the Ariadne
How long was Ariadne sleeping for?
b
*(Ja) Posi ora dhen petakse tibala i Ariadne?
For how time not threw.perf.3sg the ball Ariadne
*How long did Ariadne not throw the ball for?
c
For how time not threw.imperf.3sg the ball Ariadne
How long was Ariadne in the state of not throwing the ball?
(Ja) Posi ora dhen petuse ti bala i Ariadne?

In $(67 \mathrm{a}, \mathrm{c})$ we see that how long is compatible with a progressive. But in (67b) we have a negated perfective of an eventive verb, and how long, and its Greek counterpart, are ungrammatical. If negation were able to operate as in (65) we would expect (67b) to be good, in English as well as in Greek, contrary to fact.

Next, consider while. This test is again based on Karttunen 1974:

a

Eplina ta pjata oso kimotane

i Ariadne. washed.perf.1sg the dishes while slept.imperf.3sg the A.

I washed the dishes while Ariadne was asleep.

b *Eplina ta pjata oso dhen petakse tibala i Ariadne. Washed the dishes while not threw.perf.3sg the ball $A$.

*I washed the dishes while Ariadne didn't trow the ball.

c Eplina ta pjata oso dhen petuse tibala i Ariadne. Washed the dishes while not threw.imperf.3sg the ball A. I washed the dishes while Ariadne was in the state of not throwing the ball.

Again, we see that true stative forms, as in $(68 \mathrm{a}, \mathrm{c})$ admit while. The negated perfective past, however, does not: did not throw the ball in (68b) is not equivalent to being a state of not throwing the ball in (68c).

Third, consider in and for adverbials, and their Greek counterparts:

I Ariadni itan distixismeni $\left\{\mathrm{ja} /{ }^{*} \mathrm{se}\right\}$ pola xronia.

the A. was unhappy for/in many years

Ariadne was unhappy $\{$ for $/ *$ in $\}$ many years. 
(70) a I Ariadni ksipnise Ariadne woke up (perf.)

b I Ariadni dhen ksipnise Ariadne didn't wake up (perf.)

c

I Ariadni dhen ksipnuse

$\{\mathrm{se} / *$ ja $\} 10$ lepta.

$\{$ in/*for $\} 10$ minutes.

$\{\mathrm{se} / *$ ja $\} 10$ lepta.

$\left\{\mathrm{in} / *_{\text {for }} 10\right.$ minutes.

$\{\mathrm{ja} / \mathrm{se}\} 10$ lepta.

Ariadne didn't wake up (imperf.) $\{$ in/for $\} 10$ minutes.

Here we see that the negated perfective form remains imcompatible with a for/jaadverbial (70b), unlike true statives.

Finally, consider imperatives. Imperatives are known to not be compatible with stative meanings. If negation is a stativizer, then we expect negative perfectives to be bad imperatives. In the paradigm below, however, we see that they are not:
a $\quad *$ Gnorize tin apandisi!
*Know the answer!
b Diavase to grama!
Read(perf.) the letter!
c Mi diavasis to grama!
Don't read(perf.) the letter!

The sentences above are not equivalent in terms of stativity. Only (71a) is a true stative and excluded from the imperative. The negative forms are interpreted eventively and are thus fine.

These facts show clearly that the analysis of negation as a stativizer, even in its most recent reincarnation (65), cannot be correct, and must therefore be abandoned (for a similar position see Kamp and Reyle 1993).

\section{Mexri, para monon and prin 'before'}

In this final section, I examine a problematic aspect of Karttunen's original account: the alleged equivalence between until and before under negation. I point out two asymmetries between dhen \{para monon/mexri\} and dhen prin 'before' which support the position that there is no equivalence. The discussion will be very brief, given space limitations, but the point should be clear.

The first asymmetry is that with achievements, the prin-clause becomes the focus of negation, and does not imply actualization. This reading is NOT equivalent to the NPI para monon reading.

I prigipisa dhen eftase prin apo ta mesanixta. (Eftase argotera i den eftase kan.)

'The princess did not anrive before midnight. (In fact, she arrived (much) later than that. Or she didn't arrive at all.).

$$
\left.\left.\exists t \text { [midnight }(t) \wedge t<n \wedge \neg \exists e \exists t^{\prime}\left[t^{\prime}<t \wedge \text { arrive (princess, } e, t^{\prime}\right)\right]\right]
$$

The before-sentence has a purely temporal reading, and the arriving event is just an implicature. Compare this to the para monon version (38), where an arriving event is part of the meaning.

Second, the Mittwoch reading is NOT available with prin and an imperfective stative. Compare the mexri sentence (74) which has the stative meaning in (75) to the prin version in (76), which only has a habitual reading: 
I prigipisa dhen kimotane mexri ta mesanixta. the princess not slept.imperf.3sg until the midnight 'The princess was in a state of not-sleeping until midnight.'

$[[(7 \mathrm{~b})]]=\exists s \exists t \exists t t^{\prime} \exists t^{\prime \prime},\left[\neg\right.$ sleep (princess, s) $\wedge \mathbf{A T}\left(s, t,{ }^{\prime \prime}\right) \wedge t t^{\prime \prime}<n \wedge$ midnight $\left(t^{\prime}\right) \wedge t \subseteq t^{\prime \prime}{ }^{\prime} \wedge \forall t^{\prime \prime}\left[\left[t \leq t^{\prime \prime} \leq t^{\prime}\right] \rightarrow \exists s^{\prime}\left[s^{\prime} \subseteq s \wedge \neg\right.\right.$ sleep (princess, $\left.\left.\left.\left.s^{\prime}\right) \wedge \mathbf{A T}\left(s^{\prime}, t^{\prime \prime}\right)\right]\right]\right] \quad$ (Mittwoch reading)

(76) I prigipisa dhen kimotane prin apo ta mesanixta. the princess not slept.imperf.3sg before the midnight

NOT: 'The princess was in a state of not-sleeping until midnight.'

YES: There was a period during which the princess had the habit of not going to bed before midnight.

The essence is this: there is no event actualization at the BEFORE time, but there is at the UNTIL time. This contrast yields the difference in status between the sentences below:

(77) a I prigipisa dhen pandreftike prin pethani. 'The princess did not get married before dhe died.'

b $\exists t \exists e$ [die (princess, $e, t) \wedge t<n \wedge \neg \exists e^{\prime} \exists t^{\prime}\left[t^{\prime}<t \wedge\right.$ get-married (princess, $\left.\left.\left.e^{\prime}, t^{\prime}\right)\right]\right]$

(78) a \#I prigipisa dhen pandreftike para monon otan pethane. '\#The princess did not get married until dhe died.'

$\mathrm{b} \quad \# \exists t \exists e \exists e^{\prime}$ [die (princees, $\left.e, \mathrm{t}\right) \wedge t<n \wedge$ get-married (princess, $\left.e^{\prime}, t\right) \wedge \neg \exists e^{\prime \prime} \exists t^{\prime}\left[t^{\prime}<t \wedge\right.$ get-married (princess, $\left.\left.\left.e^{\prime \prime}, t^{\prime}\right)\right]\right]$

BEFORE contributes only a temporal scale and no event, but NPI-UNTIL is eventive, as I proposed in (39). The impression of equivalence is due to scalarity which is the common feature in both prin/before and until/para monon.

\section{Conclusions}

In this paper I presented a novel argument for Karttunen's ambiguity thesis for until, based on the fact that there is crosslinguistic evidence for a lexical distinction between stative UNTIL and NPI-UNTIL. Most importantly, it was shown that the two UNTILs are not truth-conditionally equivalent under negation. Durative UNTIL has a clear stative reading which allows actualization of an event only as an implicature, but NPI-UNTIL is eventive: actualization is an entailment. Unlike positive sentences with until, English past sentences with negation, with stative as well as eventive verbs, systematically entail actualization, hence licensing only NPI-until. In Greek, stative UNTIL is also allowed with negation, but only with imperfective forms.

The wider implication of this analysis is that the account of negation as an aspectual operator that yields states must be abandoned: unlike verbal aspect, negation does not seem to have any effect on the eventuality type of a verb.

I would like to close with two comments. First, we saw that the difference between English and Greek suggests that the English simple past has a perfective default value. This raises the question of what happens if we have an actual imperfective form, e.g. a progressive: 
The princess was not writing a letter until midnight.

Interestingly, this sentence does not have the stative reading expected with durative until; it has only a futurate reading equivalent to 'there was a plan for the princess to write a letter, and that plan came into existence only at midnight'. This is the eventive reading, and the event is an implicit planning event. The futurate reading, then, seems to block stative until, and future research is needed to show why this is so-the related question of why it is that the progressive licenses futurate interpretations is certainly also relevant.

Second, it is worth pointing out that accepting the ambiguity thesis is not at all a retreat-as the non-ambiguists put it - because the ambiguity is not accidental. When we consider the larger picture, the meaning of UNTIL crosslinguistically turns out to be a cluster of meanings, including, next to the two identified here, also a purely temporal meaning that appears primarily in future sentences:

a Tha to telioso afto mexri avrio.

'I will finish this by (*until) tomorrow.'

b Ich erledige das bis morgen.

'I will do this by tomorrow.'

English employs by for this reading, but German and Greek employ their stative UNTIL words, mexri and bis. It is easy to see the similarity between the UNTIL-by and stative UNTIL: they both introduce an interval with the UNTIL argument as its right boundary. But unlike stative UNTIL, UNTIl-by contributes just that, and it then can be asserted that an event takes place at some subinterval (see Giannakidou 2002 for more). Hence the observed ambiguities all involve a common core: UNTIL contributes an interval upon which eventualities are mapped: states (stative UNTIL), or events (the other two meanings). It is then only expected that languages may use a single expression to indicate two, or possibly even all three of the relevant meanings.

\section{Endnotes}

* For valuable discussion, data, and judgments many thanks to Melody Clark, Marcel den Dikken, Peter Frase, Gunnar Ólafur Hansson, Jack Hoeksema, and Jason Merchant. Earlier versions of some of this material were presented at talks at the Universities of Amsterdam and Chicago, and the Workshop on Temporal Relations in Discourse, organized by the European Science Foundation in Lyon, France, February 2000. Many thanks to the audiences of these events for the their feedback, in particular Jan de Jong, Hans Kamp, Alice ter Meulen, Jerry Sadock, Martin Stokhof, and the many French-speaking linguists in Lyon who confirmed that jusqu' $a$ is not so good with negation. Many thanks also to the audience of SALT 12 for their comments, especially Cleo Condoravdi and Hana Filip. This research is supported by the Royal Dutch Academy of Sciences (KNAW), whose contribution is hereby gratefully acknowledged.

1. Karttunen argues for a systematic ambiguity of statives, but the inchoative meaning can be seen as a result of modification by perfective aspect, which is indeed an option with statives, as we see below in Greek. What we see overtly in Greek can be argued to happen covertly in English.

2. There is no telicity involved in the Greek perfective forms, unlike e.g. Slavic 
aspect, as I indicated in Giannakidou 2002. Greek aspect differs from Slavic in another important respect: in Slavic, aspect seems to apply at Aktionsart (hence it is more lexical in this sense). Greek aspect modifies verb meanings at a higher level. The absence of telicity is related to this fact.

3. The behavior of the PNP is related to the well-known fact (Giorgi and Pianesi 1997) that, even in languages with no obligatory aspect such as English, eventives do not allow episodic interpretations in the present-- episodic as referring to a single event (Giannakidou 2001), e.g. Bob kisses Mary. = Bob has the habit of kissing Mary. NOT: There is an event of Bob kissing Mary. As I said, this is obviously due to the fact that $n$ is conceptualized as an interval, and does not allow for a perfective event. If an event is in progress, an imperfective form will be used instead, e.g. a progressive.

4. Hence speaking about statives or eventives seems redundant in this context, as V-meanings on their own do not contain states or events. Another way of looking at this is to say that the bare V-meaning is actually a family of meanings, and that each aspect triggers the meaning compatible with it, e.g. perfective aspect will trigger the eventive meaning with statives. The choice between the two ways of formulating seems harmless, at least for the present purposes. For more discussion, see Giannakidou 2002.

5. Consider also the evidence that comes from clefts: negation and UNTIL cannot be separated at surface structure, a restriction typical of PIs:

(i) $\quad \mathrm{a}$

Dhen itan \{para monon/*mexri\} (s)tis 10 pu efije i Ariadne.

It was not until

ten o' clock that Ariadne left.

*Itan \{para monon/mexri\}(s)tis 10 pu dhen efije i Ariadne.

* It was until ten o' clock that princess didn't leave.

b

*It was until 10 o'clock that the princess didn't sleep.

In support of the PI-analysis, an altavista search performed by Jack Hoeksema indicated zero occurrences of "It was until X that".

\section{References}

Bennet, Michael, and Barbara Partee. 1972. Toward a Logic for Tense and Aspect in English. IULC , Indiana University.

Bonomi, Andrea. 1997. The progressive and the structure of events. Journal of Semantics 14: 173-205.

Clark, Melody. In preparation. Aspect and Polarity. PhD thesis, Univ. of York.

Declerk, R. 1995. The problem of not...until. Linguistics 33: 51-98.

Giannakidou, Anastasia. 1998. Polarity Sensitivity as (Non)veridical Dependency. John Benjamins, Amsterdam, Philadelphia.

Giannakidou, Anastasia. 1999. Affective dependencies. Linguistics and Philosophy 22: 367-421.

Giannakidou, Anastasia. 2001. The meaning of free choice. Linguistics and Philosophy 24: 659-735.

Giannakidou, Anastasia. 2002. A puzzle about UNTIL and the present perfect. To appear in Artemis Alexiadou, Monika Rathert, and Amim von Stechow (eds), Perfect Explorations. Mouton, de Gruyter.

Giannakidou, Anastasia and Frans Zwarts. Temporal, aspectual operators and (non)veridicality. To appear in Alessandra Giorgi, James Higginbotham, and Fabio Pianesi (eds). Oxford UPress.

Giorgi, Alessandra and Fabio Pianesi. 1997. Tense and Aspect: from Semantics to Morphosyntax. Oxford University Press.

Hitzeman, Janet. 1991. Aspect and adverbials. In SALT 1. 107-127. 
Holton, David, Peter Mackridge, and Irene Philippaki-Warburton. 1997. Greek: A comprehensive grammar of the modern language. Routledge.

Horn, L. 1989. A Natural History of Negation. University of Chicago Press.

Kamp, Hans and Uwe Reyle. 1993. From Discourse to Logic. Chapter 5: Tense and Aspect, pp. 483-679. Kluwer, Dordrecht.

Karttunen, Lauri. 1974. Until. Chicago Linguistic Society 10: 283-297.

Katz, Graham. 2000. On the stativity of the English Perfect. Paper presented at the Workshop on the Perfect, Aristotle University of Thessaloniki.

Klima, E.S. 1964. Negation in English. J. Fodor \&J. Katz (eds.), The Structure of Language.

Krifka, Manfred, 1989. Nominal reference, temporal constitution, and quantification in event semantics. In R. Bartsch, J. van Benthem and P. van Emde Boas (eds) Semantics and Contextual Expressions. Foris, Dordrecht, pp. 75-115.

Landman, Fred. 1992. The progressive. Natural Language Semantics 1: 1-33.

Mackridge, Peter. 1985. The Modern Greek Language. Oxford Univ. Press.

Mittwoch, Anita. 1977. Negative sentences with until.CLS 13: 410-417.

Seuren, Pieter. 1974. "Negative's travels". Semantic Syntax, Oxford, OUP.

de Swart, Henriette. 1996. Meaning and use of not... until. Journal of Semantics 13: 221-263.

de Swart, Henriette and Arie Molendijk. 1999. Negation and the temporal structure of narrative discourse. Journal of Semantics 16, 1-43.

Tovena, Lucia. 1995. When negation meets a temporal connective. Workshop on Time, Space, and Movement. 41-44. Université de Paul Sabatier.

Verkuyl, Henk. 1993. A Theory of Aspectuality: the Interaction between Temporal and Atemporal Structure. Cambridge University Press.

Vogeleer, Svetlana, 1999. What is negated in French negative sentences with avant que and jusqu'a complements? To appear in Going Romance 1999

Zucchi, Sandro. 1998. Aspect Shift. In Susan Rothstein (ed.), Events and Grammar. 349-370. Kluwer, Dordrecht.

Zucchi, Sandro.1999. Incomplete events, intensionality, and imperfective aspect. Natural Language Semantics 7: 179-215. 